\title{
Analysis of the inhibitory effects of $m i R-124$ and miR-152 on human epithelial ovarian cancer xenografts in a nude mouse model
}

\author{
WEIWEI LIU $^{1 *}$, LIXIA ZHANG $^{1 *}$, JING WANG $^{2}$, XIAOLI WANG $^{1}$ and HONG SUN ${ }^{1}$ \\ ${ }^{1}$ Department of Gynecology, Yidu Central Hospital of Weifang, Weifang, Shandong 262500; \\ ${ }^{2}$ Department of Gynecology, The Second People's Hospital of Dezhou, Dezhou, Shandong 253000, P.R. China
}

Received April 6, 2018; Accepted October 4, 2018

DOI: $10.3892 / \mathrm{ol} .2018 .9612$

\begin{abstract}
This study investigated the inhibitory effects of $m i R-124$ and $m i R-152$ on the growth of human ovarian cancer (OC) SKOV3 cell line subcutaneous xenografts in nude mice. Twenty-eight healthy nude mice were selected and divided into the experimental group $1(n=4)$, experimental group $2(n=4)$, negative control group $1(n=4)$, negative control group $2(n=4)$, blank control group $1(n=4)$, blank control group $2(n=4)$ and observation group $(n=4)$ according to the principle of similarity in body weight. The transfected SKOV3 cells were inoculated subcutaneously into the nape of the nude mice. After tumorigenesis, miR-124 mimics, $m i R-152$ mimics, and their negative controls were transiently transfected into human OC SKOV3 cells via lipofection method. The expression levels of $m i R-124$ and $m i R-152$ were detected via reverse transcription-quantitative polymerase chain reaction (RT-qPCR), and those of $\mathrm{Ki}-67$ and caspase-3 were detected by western blotting. After transfection, the expression levels of $m i R-124$ and $m i R-152$ in the SKOV3 cells were significantly upregulated. The nude mice were sacrificed 36 days later, and tumor nodes of nude mice transfected with $m i R-124$ and $m i R-152$ grew slowly. Compared with that in the experimental groups, tumor size in the blank control and negative control groups was gradually increased with the increment of days $(\mathrm{P}<0.05)$. The volume of subcutaneous xenografts in nude mice of $m i R-124$ and $m i R-152$ experimental groups was obviously smaller than that in the blank control and negative control groups $(\mathrm{P}<0.05)$. Besides, the inhibition of tumor size in the observation group was more significant than
\end{abstract}

Correspondence to: Dr Jing Wang, Department of Gynecology, The Second People's Hospital of Dezhou, 55 Fangzhi Street, Dezhou, Shandong 253000, P.R. China

E-mail: uk27vq@163.com

*Contributed equally

Key words: miR-124, miR-152, ovarian cancer, nude mouse model, SKOV3 cell that in the experimental groups $(\mathrm{P}<0.05)$. Thus, miR-124 and $m i R-152$ inhibit the growth of human epithelial OC xenografts in nude mice, and they are expected to become new targets for gene-based therapy of OC.

\section{Introduction}

Epithelial ovarian cancer (EOC) is a malignant tumor with the highest incidence rate in ovarian cancer (OC). According to statistics, EOC patients account for more than $80 \%$ of OC patients, and approximately 120,000 EOC patients die each year around the world, showing an increasing trend year by year (1). The occurrence and pathogenesis of EOC have remained unclear through the study on EOC for years (2). EOC has high malignancy, rapid development, and no good biological or molecular markers in the early diagnosis. Many patients are in the middle and late stages when attending the hospital (3). Besides, its prognosis is not ideal, and statistics reveal that the 5-year survival rate of patients with advanced EOC is not $>30 \%$. Therefore, a practical and effective treatment method is needed in clinical practice (4).

A micro ribonucleic acid (miRNA) is a small non-coding RNA molecule with a length of approximately 21-25 nucleotides (5). miRNAs are involved in such important cell physiological processes as cell regulation, energy metabolism, and apoptosis, which can degrade mRNA or inhibit protein translation by binding to the $3^{\prime}$ untranslated region (UTR) of downstream target genes. At present, many studies on miRNAs have revealed that miRNAs become more closely related to mental illness, cardiovascular disease and tumors $(6,7)$. In particular, in the research of tumors, miRNAs participate in the occurrence, development, diagnosis, treatment and prognosis of tumors, and different miRNAs are differentially expressed in different tumors (8). Moreover, literature has manifested that expression of both miR-124 and miR-152 are low in EOC, which can significantly inhibit the proliferation of SKOV3 cells $(9,10)$.

Therefore, a nude mouse model of subcutaneous xenografts was established in this experiment to observe the inhibitory effects of $m i R-124$ mimics and $m i R-152$ mimics on tumors, thus inserting new ideas and laying a foundation for clinical treatment of EOC. 
Table I. Gene sequences.

\begin{tabular}{lll}
\hline Gene name & \multicolumn{1}{c}{ Forward primers } & \multicolumn{1}{c}{ Reverse primers } \\
\hline miRNA-124 & 5'-GATACTCATAAGGCACGCGG-3' & 5'-GTGCAGGGTCCGAGGT-3' \\
miRNA-152 & 5'-CCAGCTCAGTGCATGACAGA-3' & 5'-GTGCAGGGTCCGAGGTATTC-3' \\
U6 & 5'-CGCTTCGGCAGCACATATAC-3' & 5'-CAGGGGCCATGCTAATCTT-3' \\
\hline
\end{tabular}

\section{Materials and methods}

Main reagents and materials. Human OC SKOV3 cells (cat. no. FDCC-HLC207) were purchased from Shanghai Ruilu Biotechnology Co., Ltd. (Shanghai, China). A total of $10 \%$ bovine fetal serum (FBS), Roswell Park Memorial Institute (RPMI)-1640 medium, Lipofectamine ${ }^{\circledR} 2000$, and TRIzol reagents (cat. nos. 10099141, 61870044, 11668019 and 15596026, respectively) were purchased from Invitrogen; Thermo Fisher Scientific, Inc. (Waltham, MA, USA). Reverse transcription-quantitative polymerase chain reaction (RT-qPCR) kit was purchased from Sigma-Aldrich (QR0100; St. Louis, Missouri, USA) and complementary deoxyribonucleic acid (cDNA) synthesis kit were purchased from Roche Diagnostics (cat.no. 11483188001; Basel,Switzerland). Primary antibodies (rabbit anti-mouse caspase-3, Ki-67 and $\beta$-actin polyclonal antibodies) and a secondary antibody [horseradish peroxidase (HRP) goat anti-rabbit antibody] (cat. nos. AC033, AF1738, A0208 and AF0003, respectively) were purchased from Shanghai Beyotime Institute of Biotechnology (Shanghai, China). miRNA-124 and miR-152 mimics, controls of mimics, and normal controls (NCs) of mimics were designed and synthesized by Shanghai GenePharma Co., Ltd. (Shanghai, China). A 7900 fluorescence real-time qPCR instrument was purchased from Applied Biosystems (Thermo Fisher Scientific, Inc.). Uv spectrophotometer Alpha-1860SPlus was purchased from Shanghai Lab-Spectrum Instruments Co. Ltd. (Shanghai, China, ).

Animal sources. A total of 28 female, specific-pathogen-free (SPF)-grade BALB/c nude mice, aged 5 weeks and weighing 18-20 g, were purchased from Beijing Weitong Lihua Experimental Animal Technology Co., Ltd. (Beijing, China). The mice were fed by designated persons in the SPF-grade animal laboratories under uniform temperature $\left(20 \pm 2^{\circ} \mathrm{C}\right)$ and humidity $(80 \pm 5 \%)$, with chow and water ad libitum. The mice were kept in separate cages with $12 \mathrm{~h}$ day and $12 \mathrm{~h}$ night.

The study was approved by the Ethics Committee of Yidu Central Hospital of Weifang (Weifang, China).

\section{Methods}

Cell culture and transfection. SKOV3 cells were cultured in RPMI-1640 medium (containing 10\% FBS), and further cultured in an incubator with $5 \% \mathrm{CO}_{2}$ at a constant temperature $\left(37^{\circ} \mathrm{C}\right)$. Then the cells were observed, and $0.25 \%$ trypsin was used for digestion and passage after they were adherent to the wall. The SKOV3 cells were inoculated on a 6-well plate to observe cell growth. When the degree of cell fusion reached approximately $80 \%$, Lipofectamine ${ }^{\circledR} 2000$ kit was applied for plasmid transfection. In this study, mice were divided into
7 groups: the observation group, the experimental group 1 ( $m i R$ 124 mimics), the experimental group 2 (miR-152 mimics), the control group 1 (NCs of $m i R$ - 124 mimics), the control group 2 (NCs of $m i R-152$ mimics), the blank group 1 (untreated cells), and the blank group 2 (untreated cells). $m i R-124$ mimics or NCs of miR-124 mimics (20 $\mu \mathrm{l})$ were added to $100 \mu \mathrm{l}$ serumfree medium, and then $3 \mu \mathrm{l}$ Lipofectamine ${ }^{\circledR} 2000$ was added. After $5 \mathrm{~min}$ of standing, the reagents were evenly mixed, followed by standing for $20 \mathrm{~min}$. Then the prepared mixed solution was added to the 6-well plate containing SKOV3 cells, and the volume was adjusted to $1 \mathrm{ml}$ using RPMI-1640 medium (without penicillin-streptomycin double antibody), and the medium was changed $6 \mathrm{~h}$ later. After transfection, the cells were collected for standby application after further culture for $48 \mathrm{~h}$. The above experiments were repeated for the transcription of $m i R-152$.

Detection of the expression levels of miR-124 and miR-152 in cells and cancer tissues via RT-qPCR. Cells or tissues were lysed by using TRIzol reagent, and the total RNA was extracted in strict accordance with the TRIzol reagent manufacturer's protocol. Cell or tissue grinding was conducted on ice, followed by the addition of TRIzol reagent for extraction. After that, RNA concentration, purity and integrity were measured via an ultraviolet spectrophotometer and $1 \%$ denatured agarose gel electrophoresis. The optical density (OD) value of the total RNA solution: A260/A280 should be within the range of 1.8-2.1, and if it did not meet the standard, the extraction would be conducted again. Then, it was reverse transcribed to cDNA with reverse transcription kit (Beyotime, Shanghai, China). The expression levels of miR-124 and miR-152 in cells and cancer tissues after transfection were detected via RT-qPCR. $m i R-124$ and $m i R-152$ primer sequences are shown in Table I. PCR reaction system: 2' SYBR Green Taq ReadyMix for RT-qPCR $(10 \mu \mathrm{l})$, upstream and downstream primers each $0.5 \mu \mathrm{l}$, cDNA $1 \mu \mathrm{l}, \mathrm{MgCl}_{2} 0.6 \mu \mathrm{l}$ and finally added to $20 \mu \mathrm{l}$ with DEPC. PCR amplification conditions: at $95^{\circ} \mathrm{C}$ for $10 \mathrm{~min}$, $95^{\circ} \mathrm{C}$ for $45 \mathrm{sec}, 60^{\circ} \mathrm{C}$ for $45 \mathrm{sec}, 72^{\circ} \mathrm{C}$ for $45 \mathrm{sec}$, and a total of 40 cycles. $U 6$ was used as an internal reference gene, and the experiments were repeated 3 times. The results were expressed by using $2^{-\triangle \Delta C \mathrm{q}}(11)$.

Animal model establishment. A total of 28 fed nude mice $(\mathrm{BALB} / \mathrm{c})$ were divided into 7 groups [the observation group, $m i R-124$ groups (experimental group 1, control group 1 and blank group 1), and $m i R-152$ groups (experiment group 2, control group 2 and blank group 2)] with 4 mice each according to the principle of similarity in body weight. After cells were transfected for $24 \mathrm{~h}$ (the density of cells was adjusted to $5 \times 10^{6}$ cells/well by resuspension in serum-free medium), they were subcutaneously injected in the right axillary fossa of nude mice. After 1 week, tumorigenesis was observed, and the tumor 
Table II. The expression of miRNA-124 and miRNA-152 mimics in SKOV3 cells after transfection.

\begin{tabular}{lcc}
\hline Groups & $m i R N A-124$ & $m i R N A-152$ \\
\hline Experimental & $7540.50 \pm 1153.50$ & $8210.00 \pm 1284.00$ \\
Control & $0.67 \pm 0.05^{\mathrm{a}}$ & $0.74 \pm 0.08^{\mathrm{a}}$ \\
Blank & $0.64 \pm 0.07^{\mathrm{a}, \mathrm{b}}$ & $0.71 \pm 0.08^{\mathrm{a}, \mathrm{b}}$ \\
\hline
\end{tabular}

${ }^{\mathrm{a}} \mathrm{P}<0.0001$, there are significant differences compared with the experimental groups and ${ }^{b} \mathrm{P}>0.05$, there are no significant differences compared with the control groups.

size $>3 \mathrm{~mm}^{3}$ indicated successful modeling. Then the tumors in nude mice received injection. Tumors in the observation group were injected with the mixed solution of miR-124 mimics and miR-152 mimics [5 $\mu 1$ miR-124 mimics $+5 \mu 1$ miR-152 mimics $+100 \mu 1$ phosphate-buffered saline (PBS)] and $3 \mu 1$ liposomes; those in the experimental group 1 were injected with the mixed solution of miR-124 mimics (5 $\mu \mathrm{l}$ miR-124 mimics $+100 \mu \mathrm{l}$ PBS) and $3 \mu 1$ liposomes; those in the control group 1 received injection of the mixed solution of NCs of $m i R-124$ mimics $(5 \mu \mathrm{l}$ NCs of $m i R-124$ mimics $+100 \mu 1$ PBS) and $3 \mu 1$ liposomes; those in the blank group 1 underwent injection of $100 \mu \mathrm{l}$ PBS + $3 \mu \mathrm{l}$ liposomes, and the above experiments were repeated in the $m i R-152$ groups. The mice received the injection once a week for a total of 6 weeks, and the tumor size was observed. At 36 days after injection, the nude mice were sacrificed, and their tumor tissues were preserved for subsequent experiments.

Detection of the expression of Ki-67 and caspase-3 proteins in each group via western blotting. The total protein was extracted from tumor tissues of the nude mice, and lysed by the addition of the cell lysate (on ice) for $30 \mathrm{~min}$. Then the cells were crushed and centrifuged at $4^{\circ} \mathrm{C}$ and $11,500 \mathrm{x} \mathrm{g}$ for $10 \mathrm{~min}$ by using an ultracentrifuge. The supernatant after centrifugation was collected and stored in a refrigerator at $-80^{\circ} \mathrm{C}$. Afterwards, the protein concentration was determined by using bicinchoninic acid (BCA); sodium dodecyl sulfatepolyacrylamide gel electrophoresis (SDS-PAGE) buffer was added for $5 \mathrm{~min}$ of boiling, and the protein was transferred onto a polyvinylidene fluoride (PVDF) membrane after electrophoresis. A total of 5\% skim milk and tris-buffered saline with Tween-20 (TBST) solution were adopted for sealing in the dark for $2 \mathrm{~h}$, followed by washing with TBST solution. Primary antibodies (rabbit anti-mouse Ki-67 and caspase-3 polyclonal antibodies) $(1: 1,000)$ were added for incubation at $4^{\circ} \mathrm{C}$ overnight, followed by washing with PBS. After that, horseradish perxiodase labeled goat anti-rat secondary antibody $(1: 5,000)$ was added and it was incubated at $37^{\circ} \mathrm{C}$ for $1 \mathrm{~h}$, TBST was used to rinse three times, each time for $5 \mathrm{~min}$, followed by color development and grayscale measurement. $\beta$-actin was used as an experimental internal reference.Quantity One software was used to analyze the gray value. The relative expression level of protein $=$ the gray value of target protein bands/the gray value of $\beta$-actin protein bands.

Statistical analysis. In this study, Statistical Product and Service Solutions (SPSS) 20.0 software package (Beijing
Sichuang Weida Information Technology Co., Ltd., Beijing, China) was employed for statistical analysis of all the collected results. Count data were expressed as percentage (\%). The Chi-square test was applied for the comparison between the two groups. Measurement data were expressed as mean \pm standard deviation, and independent sample $t$ test was used for comparison between two groups. Single-factor ANOVA analysis was used for comparison between multiple groups, and LSD-t test was used in pairwise comparison. $\mathrm{P}<0.05$ was considered to indicate a statistically significant difference.

\section{Results}

Expression of miR-124 mimics and miR-152 mimics in SKOV3 cells after transfection. The expression of miRNA-124 and miRNA-152 mimics in SKOV3 cells after transfection was detected by RT-qPCR. The results revealed that both miRNA-124 mimics and miRNA-152 mimics in the experimental groups were obviously highly expressed in SKOV3 cells, and were remarkably higher than those in the control and blank groups, displaying statistically significant differences $(\mathrm{P}<0.01)$ (Table II).

Subcutaneous tumor growth in nude mice. The transfected SKOV3 cells were inoculated into tumors, and it was manifested in the observation of tumor condition 1 week later that the tumor size in the 7 groups of nude mice met the requirements of modeling, so the modeling was successful. At 36 days after the injection, the nude mice were sacrificed, and the measurement of their tumors demonstrated that the tumor volumes in the miRNA-124 groups were $7.88 \pm 2.84 \mathrm{~mm}^{3}$ (experimental group 1), $43.57 \pm 20.64 \mathrm{~mm}^{3}$ (control group 1) and $48.62 \pm 26.28 \mathrm{~mm}^{3}$ (blank group 1), respectively, and those in the miRNA-152 groups were $8.64 \pm 3.52 \mathrm{~mm}^{3}$ (experimental group 2), $45.74 \pm 22.31 \mathrm{~mm}^{3}$ (control group 2) and $47.27 \pm 25.88 \mathrm{~mm}^{3}$ (blank group 2), respectively, manifesting significant differences $(\mathrm{P}<0.01)$. However, it was revealed through injection that in the observation group, the volume was $3.83 \pm 1.54 \mathrm{~mm}^{3}$, which was significantly different from that in experimental group 1 and $2(\mathrm{P}<0.01)$ (Fig. 1).

Detection of the relative expression level of miRNA in animal model tissues in each group via RT-qPCR. According to the detection of the relative expression levels of miRNA-124 and miRNA-154 in the nude mouse tumor model in each group, the relative expression level of $m i R-124$ in the experimental group $1(5.84 \pm 1.67)$ was significantly higher than that in the control group $1(1.33 \pm 0.47)$ and blank group 1 $(1.28 \pm 0.32)$ among the miRNA-124 groups, with statistical differences $(\mathrm{P}<0.01$ in all comparisons). Besides, among the miRNA-152 groups, the relative expression level of miR-152 in the experimental group $2(6.34 \pm 2.17)$ was markedly higher than that in the control group $2(1.64 \pm 0.87)$ and the blank group $2(1.58 \pm 0.64)$, displaying statistical differences $(\mathrm{P}<0.01$ in all comparisons). However, the relative expression levels of miRNA-124 and miRNA-152 in the observation group were $6.21 \pm 1.84$ and $6.98 \pm 1.77$, respectively, manifesting no differences in comparisons with those in the experimental group 1 and 2 (P>0.05) (Fig. 2). 

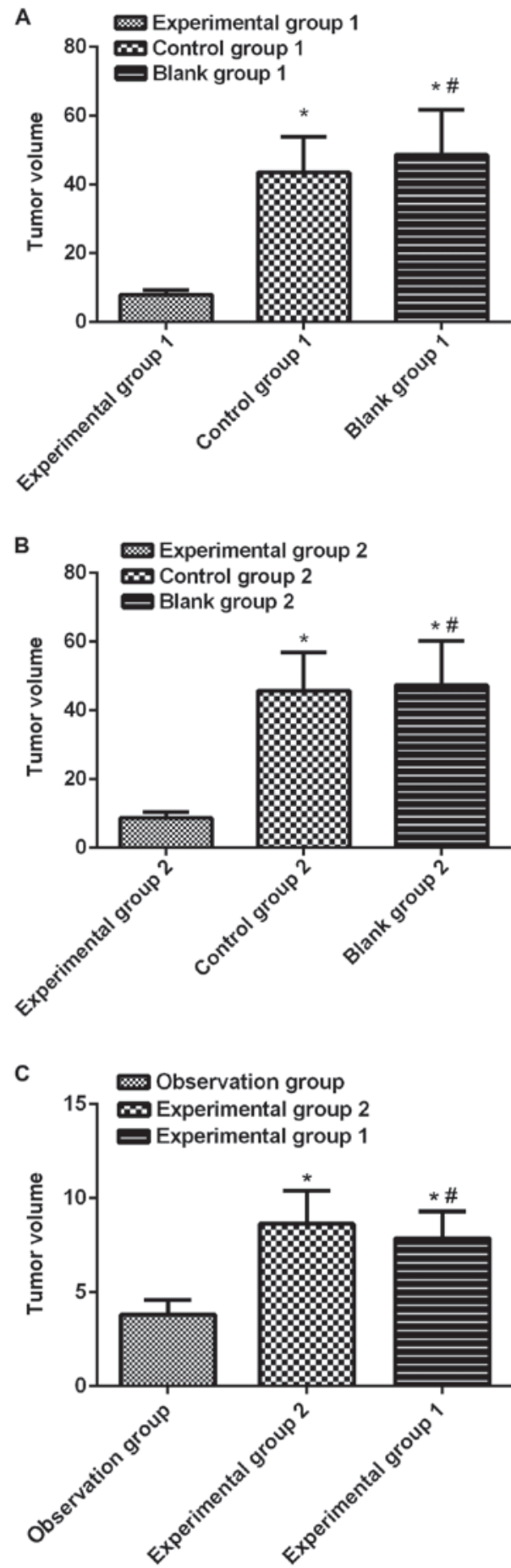

Figure 1. (A) Growth of subcutaneous tumors in nude mice in the miR-124 groups. Based on observation, it is found that the volume in the experimental group 1 is statistically different from that in the control group 1 and the blank group 1 ( $\mathrm{P}<0.01)$. (B) Growth of subcutaneous tumors in nude mice in the $m i R-152$ groups. The observation reveals that the volume in the experimental group 2 is statistically different from that in the control group 2 and the blank group 2 ("P<0.01). (C) Growth of subcutaneous tumors in nude mice in the observation group and the two experimental groups. The observation manifests that the volume in the observation group receiving injection is statistically different from that in the experimental group 1 and the experimental group $2\left({ }^{*} \mathrm{P}<0.01\right)$. (A-C) ${ }^{\#} \mathrm{P}>0.05$, not statistically significant.

Protein expression level in each group. The relative expression levels of $\mathrm{Ki}-67$ and caspase- 3 proteins were detected by means of western blotting. The results illustrated that among the Ki-67 groups, the expression level of Ki-67 in the
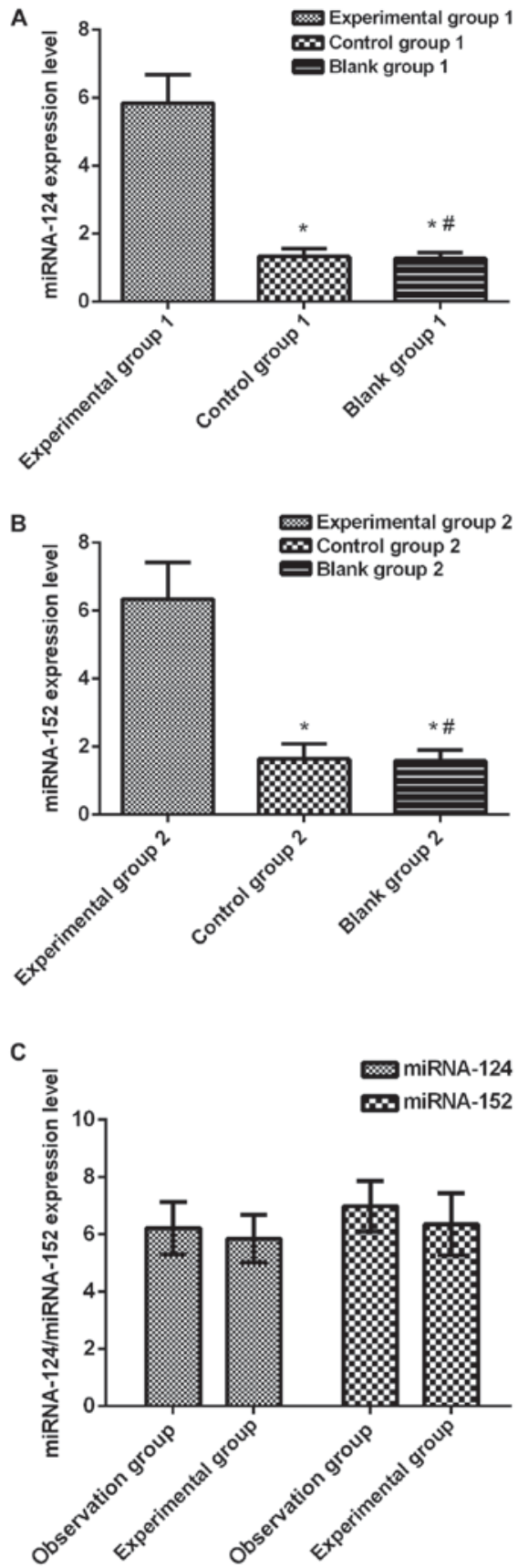

Figure 2. (A) Detection of $m i R-124$ expression in the $m i R-124$ groups via RT-qPCR. RT-qPCR detection results demonstrate that among the miRNA-124 groups, the expression level of miR-124 in the experimental group $1(5.84 \pm 1.67)$ is significantly higher than that in the control group 1 $(1.33 \pm 0.47)$ and the blank group $1(1.28 \pm 0.32)$, showing statistical differences ( $\mathrm{P}<0.01$ in all comparisons). (B) Detection of $m i R-152$ expression in groups via RT-qPCR. RT-qPCR detection results demonstrate that among $m i R-152$ groups, the expression level of $m i R-152$ in the experimental group 2 $(6.34 \pm 2.17)$ is obviously higher than that in the control group $2(1.64 \pm 0.87)$ and the blank group $2(1.58 \pm 0.62)$, displaying statistical differences $\left({ }^{*} \mathrm{P}<0.01\right.$ in all comparisons). (A and $\left.\mathrm{B}\right){ }^{*} \mathrm{P}>0.05$, not statistically significant. (C) $m i R-124$ and $m i R-152$ expression levels in the observation group and the two experimental groups. Comparisons indicate that the expression levels of $m i R-124$ and $m i R-152$ in the observation group are not statistically different from those in the two experimental groups ("P>0.05).

experimental group $1(0.492 \pm 0.084)$ was obviously lower than those in the control group $1(0.841 \pm 0.148)$ and blank group 1 $(0.813 \pm 0.137)$, manifesting statistical differences $(\mathrm{P}<0.01$ in all comparisons). The expression level of Ki-67 in the 

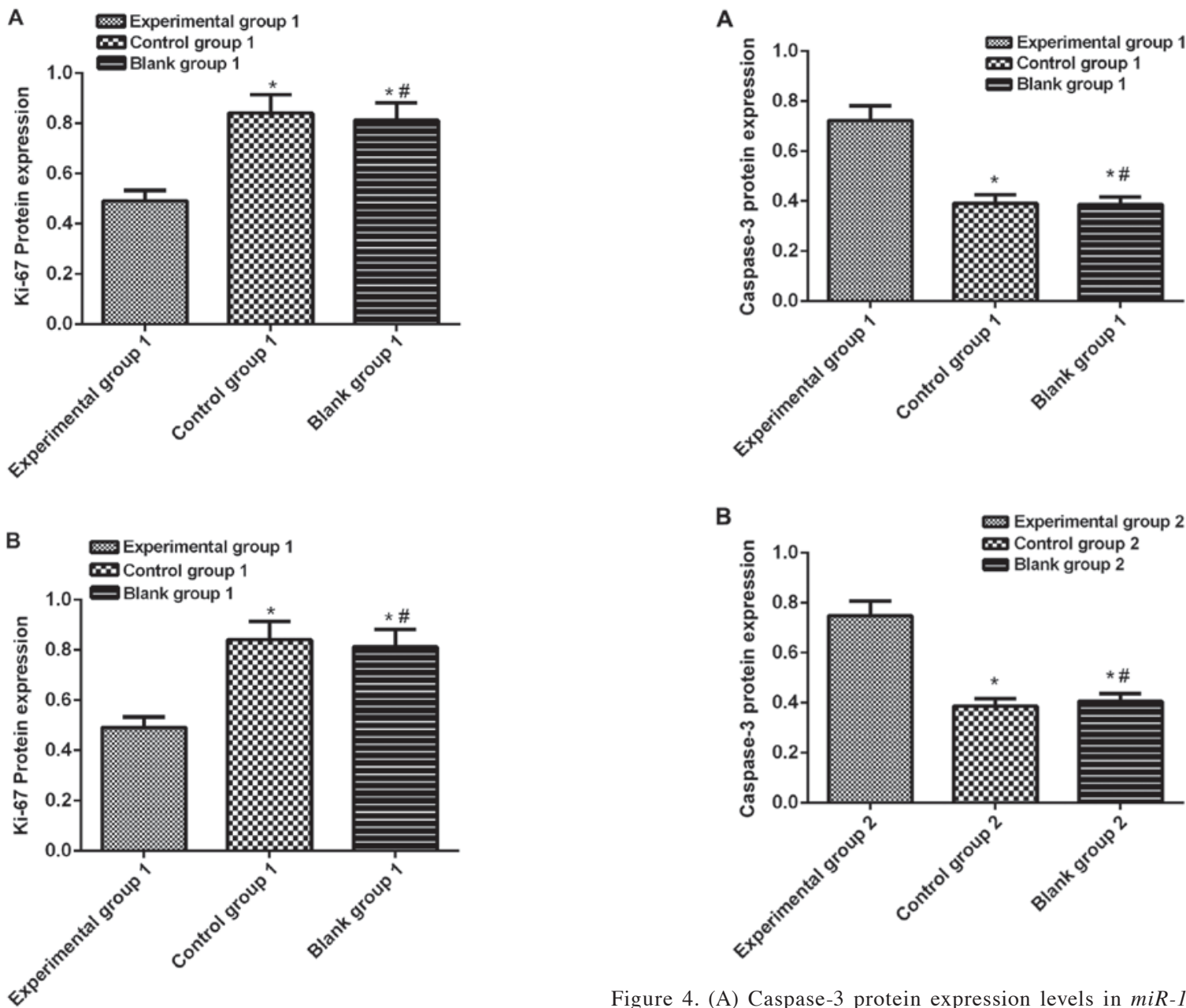

Figure 3. (A) Ki-67 protein expression levels in $m i R-124$ groups. Western blotting is applied to detect the protein expression level in each group, which reveals that the expression level of $\mathrm{Ki}-67$ in the experimental group 1 $(0.492 \pm 0.084)$ is markedly lower than that in the control group $1(0.841 \pm 0.148)$ and blank group $1(0.813 \pm 0.137)$, showing statistically significant differences (" $\mathrm{P}<0.01$ in all comparisons). (B) $\mathrm{Ki}-67$ protein expression levels in $m i R-152$ groups. Western blotting is applied to detect the protein expression level in each group, which reveals that the expression level of Ki-67 in the experimental group $2(0.501 \pm 0.084)$ is markedly low compared with that in the control group $2(0.862 \pm 0.15)$ and blank group $2(0.823 \pm 0.147)$, displaying statistically significant differences ( $\mathrm{P}<0.01$ in all comparisons). (A and $\mathrm{B}$ ) ${ }^{\#} \mathrm{P}>0.05$, not statistically significant.

experimental group $2(0.501 \pm 0.084)$ was decreased markedly compared with that in the control group $2(0.862 \pm 0.152)$ and blank group $2(0.823 \pm 0.147)$, and the differences were statistically significant $(\mathrm{P}<0.01$ in all comparisons). In addition, among the caspase- 3 groups, the expression level of caspase-3 in the experimental group $1(0.724 \pm 0.117)$ was significantly higher than that in the control group $1(0.392 \pm 0.067)$ and blank group $1(0.411 \pm 0.077)$, and the differences were statistically significant $(\mathrm{P}<0.01$ in all comparisons). The expression level of caspase- 3 in the experimental group $2(0.748 \pm 0.122)$ was elevated notably compared with that in the control group $2(0.387 \pm 0.058)$ and blank group $2(0.406 \pm 0.062)$, showing statistical differences $(\mathrm{P}<0.01)$. Nevertheless, the expression levels of $\mathrm{Ki}-67$ and caspase- 3 in the observation group were $0.506 \pm 0.088$ and $0.794 \pm 0.110$, respectively, and there were no differences in comparison with those in the experimental group 1 and 2 ( $\mathrm{P}>0.05)$ (Figs. 3-5).

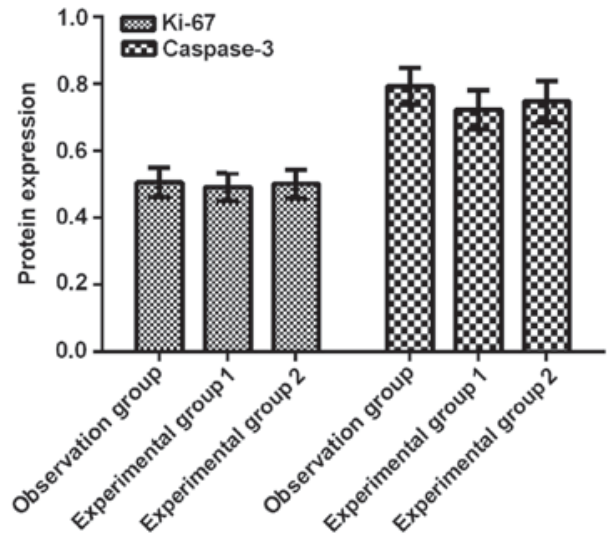

Figure 5. The expression levels of Ki-67 and caspase-3 proteins in the observation and two experimental groups. Comparisons illustrate that the expression levels of $\mathrm{Ki}-67$ and caspase- 3 proteins in the observation group are $0.506 \pm 0.088$ and $0.794 \pm 0.110$, respectively, which are not statistically different from those in the experimental group $1(0.492 \pm 0.084,0.501 \pm 0.084)$ and experimental group $2(0.724 \pm 0.117,0.748 \pm 0.122)(P>0.05)$.

Figure 4. (A) Caspase-3 protein expression levels in $m i R-124$ groups. Detection of the protein expression level in each group through western blotting indicates that the expression of caspase- 3 in the experimental group $1(0.724 \pm 0.117)$ is remarkably higher than that in the control group 1 $(0.392 \pm 0.067)$ and blank group $1(0.411 \pm 0.077)$, and the differences are statistically significant ( $\mathrm{P}<0.01$ in all comparisons). (B) Caspase-3 protein expression levels in $m i R-152$ groups. Results of western blotting in detecting the protein expression level in each group indicate that the expression of caspase- 3 in the experimental group $2(0.758 \pm 0.122)$ is increased notably compared with that in the control group $2(0.387 \pm 0.058)$ and blank group 2 $(0.406 \pm 0.062)$, and the differences are statistically significant $(" \mathrm{P}<0.01$ in all comparisons). (A and $\mathrm{B}$ ) ${ }^{\#} \mathrm{P}>0.05$, not statistically significant. 


\section{Discussion}

$\mathrm{OC}$ is one of the malignant cancers with a fairly high mortality rate in women, and it ranks sixth among cancer in women worldwide. EOC, occupying the highest proportion of cancers with the highest malignancy, is hard to be detected, and patients are in the advanced stage when diagnosed, so they lost the best time for treatment. Nowadays, early diagnosis and treatment of EOC are the major problems faced with the society (12). Cancerous adhesions triggered by late lesions of EOC cannot be completely removed during surgery, and distal metastasis may occur, which cannot be solved via surgery. These problems, in turn, are also the main causes of poor prognosis of EOC patients (13). At present, the best treatment option is surgery combined with chemotherapy as well as cisplatin and paclitaxel combined chemotherapy, but the drug resistance resulted from the long-term application makes clinical treatment efficacy worse and worse, so there is a need to find a more effective treatment method for EOC, thus alleviating the burden on patients (14).

In recent years, miRNA has become a hot topic. As a non-coding RNA molecule, miRNAs can inhibit the degradation of target genes by binding to them, causing differential expression of post-transcriptional regulatory genes. miRNAs are involved in most of the complex biological processes in the organism, especially the occurrence and development of tumors, which have attracted increasing attention from scholars (15). A study has illustrated that (16) miR-124 is expressed in a variety of cancers such as liver cancer, gastric cancer, pancreatic cancer, and OC. A study by Silber et al (17) demonstrated that the high expression of $m i R-124$ can reduce the proliferative capacity of neuroblasts and decrease the growth rate of tumorigenic cells in in vivo experiments. However, $m i R-152$ has been confirmed to play an important role in the occurrence and development of many tumors, as well as cell proliferation and apoptosis (18).

In this study, the inhibitory effects of $m i R-124$ and $m i R-152$ in EOC were investigated. An EOC animal model was successfully established, and it was revealed through the regular injection of $m i R-124$ mimics and $m i R-152$ mimics that overexpressed $m i R-124$ mimics and $m i R-152$ mimics markedly inhibited the growth of tumors. Moreover, the combined injection of $m i R-124$ and $m i R-152$ indicated that the tumor size detected by the combined injection was significantly larger than that detected via the injection of miRNA-124 mimics or miRNA-152 mimics alone. Furthermore, subsequent RT-qPCR detection results revealed that the expression of $m i R-124$ and $m i R-152$ in both experimental groups were obviously increased compared with those in other groups, manifesting significant differences, and there were no differences in comparison with the observation group. A study by Zhang et al (19) demonstrated that $m i R-124$ expression is low in OC, and this low expression is more obvious in highly metastatic OC. In addition, Shu et al (20) found from in vitro experiments that highly expressed miRNA can inhibit the proliferation, migration and invasion, and induce apoptosis of OC cells. According to the study of Zhou et al (21), the overexpression of $m i R-152$ can significantly suppress the proliferation of OC cells. The study results are similar to those of our experiment. Ki-67 protein is closely related to cell proliferation, differentiation, invasion and apoptosis and participates in the pathological processes of all malignant tumors (22). However, caspase-3 protein, as a member of the caspase family, is involved in apoptosis and is the initiator of apoptosis (23). The expression levels of Ki-67 and caspase- 3 proteins in tissues were detected via western blotting, which manifested that the expression of $\mathrm{Ki}-67$ protein in the two experimental groups was significantly lower than that in other groups, with significant differences, but there was no difference compared with that in the control groups. However, caspase-3 protein was highly expressed in the two experimental groups compared with that in the other groups, but this expression was not different from that in the observation group. The underlying cause may be the binding of miRNA-124 and miRNA-152 to downstream target genes $(24,25)$ [GLI family zinc finger 3 (Gli3) and phosphoinositide-3-kinase regulatory subunit 3 (PIK3R3)].

However, there are still some defects in this experiment. First of all, this experiment was an animal model experiment and not conducted in clinical practice. Whether the observed results are biased is not clear due to the few experimental samples. Besides, the modeling time is short, and patients were in the middle and advanced stage when they were clinically diagnosed, so we expect to carry out research through clinical trials in the future, so as to improve the treatment and prognosis of EOC.

In conclusion, $m i R-124$ and $m i R-152$ exert inhibitory effects on the growth of EOC xenografts in nude mice and are expected to serve as new targets for EOC treatment.

\section{Acknowledgements}

Not applicable.

\section{Funding}

No funding was received.

\section{Availability of data and materials}

The datasets used and/or analyzed during the present study are available from the corresponding author on reasonable request.

\section{Authors' contributions}

WL and LZ wrote the manuscript and were responsible for cell culture and transfection. JW performed PCR. XW constructed the animal model. HS contributed to performing western blotting. All authors read and approved the final manuscript.

\section{Ethics approval and consent to participate}

The study was approved by the Ethics Committee of Yidu Central Hospital of Weifang (Weifang, China).

\section{Patient consent for publication}

Not applicable.

\section{Competing interests}

The authors declare that they have no competing interests. 


\section{References}

1. Bean L, Sulzmaier FJ, Anderson KM, Tancioni I, Kolev V, Plaxe SC, McHale MT, Schlaepfer DD and Pachter J: Focal adhesion kinase (FAK) inhibition overcomes cisplatin-resistance in epithelial ovarian cancer. Gynecol Oncol 145: 97-98, 2017.

2. Phelan CM, Kuchenbaecker KB, Tyrer JP, Kar SP, Lawrenson K, Winham SJ, Dennis J, Pirie A, Riggan MJ, Chornokur G, et al; AOCS study group; EMBRACE Study; GEMO Study Collaborators; HEBON Study; KConFab Investigators; OPAL study group: Identification of 12 new susceptibility loci for different histotypes of epithelial ovarian cancer. Nat Genet 49: 680-691, 2017.

3. Kar SP, Adler E, Tyrer J, Hazelett D, Anton-Culver H, Bandera EV, Beckmann MW, Berchuck A, Bogdanova N, Brinton L, et al: Enrichment of putative PAX8 target genes at serous epithelial ovarian cancer susceptibility loci. Br J Cancer 116: 524-535, 2017.

4. Yang WL, Gentry-Maharaj A, Simmons A, Ryan A, Fourkala EO, Lu Z, Baggerly KA, Zhao Y, Lu KH, Bowtell D, et al; AOCS Study Group: Elevation of TP53 autoantibody before CA125 in preclinical invasive epithelial ovarian cancer. Clin Cancer Res 23: 5912-5922, 2017.

5. Vitsios DM, Davis MP, van Dongen S and Enright AJ: Large-scale analysis of microRNA expression, epi-transcriptomic features and biogenesis. Nucleic Acids Res 45: 1079-1090, 2017.

6. Suzuki HI, Young RA and Sharp PA: Super-enhancer-mediated RNA processing revealed by integrative microRNA network analysis. Cell 168: 1000-1014.e15, 2017.

7. Mazurek SR, Calway T, Harmon C, Farrell P and Kim GH: MicroRNA-130a regulation of desmocollin 2 in a novel mode of arrhythmogenic cardiomyopathy. Microrna 6: 143-150, 2017.

8. Bradshaw NJ, Ukkola-Vuoti L, Pankakoski M, Zheutlin AB, Ortega-Alonso A, Torniainen-Holm M, Sinha V, Therman S, Paunio T, Suvisaari J, et al: The NDE1 genomic locus can affect treatment of psychiatric illness through gene expression changes related to microRNA-484. Open Biol 7: 7, 2017.

9. Zhang L, Volinia S, Bonome T, Calin GA, Greshock J, Yang N, Liu CG, Giannakakis A, Alexiou P, Hasegawa K, et al: Genomic and epigenetic alterations deregulate microRNA expression in human epithelial ovarian cancer. Proc Natl Acad Sci USA 105: 7004-7009, 2008.

10. Taylor DD and Gercel-Taylor C: MicroRNA signatures of tumor-derived exosomes as diagnostic biomarkers of ovarian cancer. Gynecol Oncol 110: 13-21, 2008.

11. Livak K J. Schmittgen T D. Analysis of relative gene expression data using real-time quantitative PCR and the $2^{-\Delta \Delta C T}$ method. Methods 25: 402-408, 2001.

12. Baldwin LA, Chen Q, Tucker TC, White CG, Ore RN and Huang B: Ovarian cancer incidence corrected for oophorectomy. Diagnostics (Basel) 7: 7, 2017.
13. Darelius A, Lycke M, Kindblom JM, Kristjansdottir B, Sundfeldt K and Strandell A: Efficacy of salpingectomy at hysterectomy to reduce the risk of epithelial ovarian cancer: A systematic review. BJOG 124: 880-889, 2017.

14. Oronsky B, Ray CM, Spira AI, Trepel JB, Carter CA and Cottrill HM: A brief review of the management of platinumresistant-platinum-refractory ovarian cancer. Med Oncol 34: 103 , 2017.

15. Agarwal V, Bell GW, Nam JW and Bartel DP: Predicting effective microRNA target sites in mammalian mRNAs. eLife 4: 4, 2015.

16. Lin S and Gregory RI: MicroRNA biogenesis pathways in cancer. Nat Rev Cancer 15: 321-333, 2015.

17. Silber J, Hashizume R, Felix T, Hariono S, Yu M, Berger MS, Huse JT, VandenBerg SR, James CD, Hodgson JG, et al: Expression of miR-124 inhibits growth of medulloblastoma cells. Neuro-oncol 15: 83-90, 2013.

18. Dang YW, Zeng J, He RQ, Rong MH, Luo DZ and Chen G: Effects of miR-152 on cell growth inhibition, motility suppression and apoptosis induction in hepatocellular carcinoma cells. Asian Pac J Cancer Prev 15: 4969-4976, 2014.

19. Zhang H, Wang Q, Zhao Q and Di W: miR-124 inhibits the migration and invasion of ovarian cancer cells by targeting SphK1. J Ovarian Res 6: 84, 2013.

20. Shu J, Yuan L, Liu XM, Li SL and Zhou Q: The expression of miR-124 in ovarian cancer tissues and its effect on biological functions of ovarian cancer cells. Tumor 34: 430-436, 2014.

21. Zhou X, Zhao F, Wang ZN, Song YX, Chang H, Chiang Y and Xu HM: Altered expression of miR-152 and miR-148a in ovarian cancer is related to cell proliferation. Oncol Rep 27: 447-454, 2012.

22. Brown DC and Gatter KC: Ki67 protein: The immaculate deception? Histopathology 40: 2-11, 2002.

23. Dick SA, Chang NC, Dumont NA, Bell RA, Putinski C, Kawabe Y, Litchfield DW, Rudnicki MA and Megeney LA: Caspase 3 cleavage of Pax7 inhibits self-renewal of satellite cells. Proc Natl Acad Sci USA 112: E5246-E5252, 2015.

24. Wen SY, Lin Y, Yu YQ, Cao SJ, Zhang R, Yang XM, Li J, Zhang YL, Wang YH, Ma MZ, et al: miR-506 acts as a tumor suppressor by directly targeting the hedgehog pathway transcription factor Gli3 in human cervical cancer. Oncogene 34: 717-725, 2015

25. Li B, Xie Z and Li B: miR-152 functions as a tumor suppressor in colorectal cancer by targeting PIK3R3. Tumour Biol 37: 10075-10084, 2016.

This work is licensed under a Creative Commons Attribution-NonCommercial-NoDerivatives 4.0 International (CC BY-NC-ND 4.0) License. 